\title{
Aerosol hygroscopicity parameter derived from the light scattering enhancement factor measurements in the North China Plain
}

\author{
J. Chen ${ }^{1, *}$, C. S. Zhao ${ }^{1}$, N. Ma ${ }^{1, * *}$, and P. Yan $^{2}$ \\ ${ }^{1}$ Department of Atmospheric and Oceanic Sciences, School of Physics, Peking University, Beijing 100871, China \\ ${ }^{2}$ Meteorological Observation Centre, China Meteorological Administration, Beijing 100871, China \\ *now at: Earth Observatory of Singapore, Nanyang Technological University, 50 Nanyang Avenue, 639798, Singapore \\ ** now at: Leibniz Institute for Tropospheric Research, Permoserstr. 15, 04318 Leipzig, Germany
}

Correspondence to: C. S. Zhao (zcs@pku.edu.cn)

Received: 18 December 2013 - Published in Atmos. Chem. Phys. Discuss.: 6 February 2014

Revised: 24 June 2014 - Accepted: 7 July 2014 - Published: 13 August 2014

\begin{abstract}
The relative humidity (RH) dependence of aerosol light scattering is an essential parameter for accurate estimation of the direct radiative forcing induced by aerosol particles. Because of insufficient information on aerosol hygroscopicity in climate models, a more detailed parameterization of hygroscopic growth factors and resulting optical properties with respect to location, time, sources, aerosol chemistry and meteorology are urgently required. In this paper, a retrieval method to calculate the aerosol hygroscopicity parameter, $\kappa$, is proposed based on the in situ measured aerosol light scattering enhancement factor, namely $f(\mathrm{RH})$, and particle number size distribution (PNSD) obtained from the HaChi (Haze in China) campaign. Measurements show that $f(\mathrm{RH})$ increases sharply with increasing $\mathrm{RH}$, and that the time variance of $f(\mathrm{RH})$ is much greater at higher $\mathrm{RH}$. A sensitivity analysis reveals that the $f(\mathrm{RH})$ is more sensitive to the aerosol hygroscopicity than PNSD. $f(\mathrm{RH})$ for polluted cases is distinctly higher than that for clean periods at a specific RH. The derived equivalent $\kappa$, combined with the PNSD measurements, is applied in the prediction of the cloud condensation nuclei $(\mathrm{CCN})$ number concentration. The predicted CCN number concentration with the derived equivalent $\kappa$ agrees well with the measured ones, especially at high supersaturations. The proposed calculation algorithm of $\kappa$ with the $f(\mathrm{RH})$ measurements is demonstrated to be reasonable and can be widely applied.
\end{abstract}

\section{Introduction}

Atmospheric aerosols contribute significantly to the uncertainties in the prediction of climate radiative forcing (IPCC, 2007). Aerosol optical properties are crucial input parameters for accurate estimation of the direct radiative forcing caused by aerosols in climate models. Covert et al. (1972) indicated that aerosol hygroscopicity can affect their optical properties via changing the particle size and refractive index, and hence influence the climatic and environmental effects of aerosols. As a result, the relative humidity $(\mathrm{RH})$ dependence of aerosol optical properties, e.g. light scattering, is a key factor to the estimation of aerosol radiative forcing (Charlson et al., 1992; Schwartz, 1996). For better simulation and prediction of radiative transfer, along with aerosol relevant physical processes, parameterized forms of aerosol hygroscopic growth factors are usually required in general circulation models (GCMs). However, detailed information of aerosol hygroscopicity is always insufficient for the model input of GCMs. This therefore calls for more comprehensive description and corresponding parameterization of aerosol hygroscopicity.

The RH dependence of light scattering (denoted by $f(\mathrm{RH}))$ is one of the physical parameters commonly applied to describe aerosol hygroscopicity. It is usually defined as the ratio of aerosol light scattering coefficients at a given $\mathrm{RH}\left(\sigma_{\mathrm{sc}}(\mathrm{RH})\right)$ and at dry condition $\left(\sigma_{\mathrm{sc}, \text { dry }}\right)$, namely $f(\mathrm{RH})$ $=\sigma_{\mathrm{sc}}(\mathrm{RH}) / \sigma_{\mathrm{sc}, \text { dry }}$. Numerous studies have demonstrated that the parameterized $f(\mathrm{RH})$ can be generally expressed as an exponential function of RH (Covert et al., 1972; Fitzgerald et al., 1982; Carrico et al., 1998, 2000, 2003; Kotchenruther 
et al., 1999; Hegg et al., 2002; Randriamiarisoa et al., 2006; Cheng et al., 2008; Pan et al., 2009; Fierz-Schmidhauser et al., 2010a, b, c; Zieger et al., 2010, 2013). It should be noted that, different from the size-resolved aerosol diameter growth factor $(g(\mathrm{RH})), f(\mathrm{RH})$ represents the overall aerosol light scattering enhancement factor of the aerosol population, and is jointly determined by the particle number size distribution (PNSD), chemical composition, density and refractive index. Additionally, the particle morphology changes can also strongly affect the aerosol optical and hygroscopic properties, leading to significant impact on $f(\mathrm{RH})$. Pagels et al. (2009) found that the transformation of soot particles to spherical droplets can be achieved in several hours with atmospheric aging processes. With increasing RH and mass fraction of condensed soluble materials onto fresh soot, the light scattering and absorption of soot particle could be evidently enhanced (Khalizov et al., 2009; Pagels et al., 2009).

Pilat and Charlson (1966) attempted to measure the aerosol light scattering enhancement factor with a tandem integrating nephelometer. In the following studies, Covert et al. (1972) introduced a measuring method to determine the $f(\mathrm{RH})$ at a set $\mathrm{RH}$ value with a humidified integrating nephelometer. More recently, the principle of humidified nephelometry has been improved (Fierz-Schmidhauser et al., 2010a-c). By adding a fast temperature and RH feedback controller to the humidified nephelometer and maintaining a stable reference $\mathrm{RH}$, a quick, automated response of the scanned $\mathrm{RH}$, and $f(\mathrm{RH})$ can be achieved.

With the above-mentioned hygroscopicity measurement technologies, numerous $f(\mathrm{RH})$-related observations have been successively conducted worldwide. In the studies of Malm and Day (2001) and Malm et al. (2003), results showed that aerosol can still take up water in a relatively low $\mathrm{RH}$ range of $20-30 \%$ RH. Nessler et al. (2005) found that $f(\mathrm{RH})$ is highly dependent on the mean particle diameter at a constant $\mathrm{RH}$. By measuring and modelling $f(\mathrm{RH})$ for various aerosol types, comparison results reveal that the $f(\mathrm{RH})$ for marine aerosols (Carrico et al., 1998, 2000, 2003; McInnes et al., 1998; Gasso et al., 2000; Wang et al., 2007; FierzSchmidhauser et al., 2010b; Zieger et al., 2010) is generally higher than that for either urban (Fitzgerald et al., 1982; McInnes et al., 1998; Yan et al., 2009; Zieger et al., 2011) or continental aerosols (Sheridan et al., 2001; FierzSchmidhauser et al., 2010c; Zieger et al., 2012, 2013). The $f(\mathrm{RH})$ for mineral dust and freshly emitted biomass burning aerosols is significantly lower (Kotchenruther and Hobbs, 1998; Li-Jones et al., 1998; Carrico et al., 2003; Kim et al., 2006; Fierz-Schmidhauser et al., 2010a; Zieger et al., 2012). It is worth noting that the $f(\mathrm{RH})$ for marine aerosols would show a decrease under strong anthropogenic influence (McInnes et al., 1998; Gasso et al., 2000; Wang et al., 2007; Fierz-Schmidhauser et al., 2010b; Zieger et al., 2010).

In the current research on aerosol hygroscopic and activation properties, one essential mission is to reliably predict the number concentration of cloud condensation nuclei (CCN).
It is known that, at a given supersaturation, the aerosol activation ability is determined primarily by the particle size and secondarily by aerosol hygroscopicity (Seinfeld and Pandis, 1998). The online, continuous observations of PNSD can be easily achieved using commercial instruments. However, direct measurements of aerosol hygroscopicity are relatively much more difficult and demand custom instrumental systems. In this work, we attempt to derive the hygroscopicity parameter, $\kappa$, with the measured $f(\mathrm{RH})$. Analogous work had been reported by Ervens et al. (2007). In the proposed approach, they have made the assumption that the aerosol simply consisted of a soluble fraction of ammonium sulfate and an unspecified insoluble component. By varying the insoluble mass fraction, with modulating the comparison results between the measured and calculated $f(\mathrm{RH})$ at a specific $\mathrm{RH}$ to the minimum deviation, the aerosol hygroscopicity parameter can be obtained. It therefore provides a possible way for the prediction of aerosol activation property, hence building a bridge for the estimation of $\mathrm{CCN}$ number concentration with the measured PNSDs. We show that the retrieval algorithm for $\kappa$ based on $f(\mathrm{RH})$ measurements is of significant utility and applicability.

Recently, with the rapid economic growth, along with the sharp expansion of the industrialization and urbanization, most megacities in the North China Plain (NCP) have inevitably experienced severe aerosol pollution. Liu et al. (2009) found that the average surface level number concentration of aerosols within $0.12-3.0 \mu \mathrm{m}$ was about $6600 \mathrm{~cm}^{-3}$; whilst the annual mean (2005-2006) aerosol mass concentration of particles smaller than $2.5 \mu \mathrm{m}\left(\mathrm{PM}_{2.5}\right)$ was reported to be as high as $118.5 \pm 40.6 \mu \mathrm{g} \mathrm{m}^{-3}$ (Yang et al., 2011). Resulting aerosol pollution episodes, as well as the aerosol-related environmental and health effects, have aroused great public concern. Considering the unique physical and chemical characteristics of aerosol particles in this region, research on aerosol hygroscopicity is of special necessity. Previous studies indicated that aerosols in the highly polluted NCP are highly hygroscopic (Liu et al., 2011). Consequently, hygroscopic growth of the aerosol will have an immense impact on aerosol optical properties and cloud droplet activation (Deng et al., 2011; Chen et al., 2012). Nevertheless, due to the limitations of measurement technologies, it is relatively difficult to directly measure aerosol hygroscopicity, and hence the existing research results are insufficient (Massling et al., 2009; Meier et al., 2009). Because measurement of aerosol light scattering enhancement with integrating nephelometers is more feasible and practical, many measurements of $f(\mathrm{RH})$ have been carried out in the NCP, while relevant studies on $f(\mathrm{RH})$ in the northern part of the NCP are relatively scarce (Pan et al., 2009; Yan et al., 2009). For better estimation of the radiative forcing by aerosols in the $\mathrm{NCP}$, a comprehensive description of aerosol hygroscopicity and parameterized hygroscopic growth factors are urgently needed in climate models. 
In this study, a 20-day well-maintained $f(\mathrm{RH})$ observation, obtained from the Haze in China (HaChi) field campaign conducted in Wuqing, Tianjin, is analysed. Statistical characteristics of $f(\mathrm{RH})$ in the northern part of the NCP region, along with their variations under different pollution levels, are investigated. A sensitivity analysis on dominating influence factors of $f(\mathrm{RH})$ is carried out, and the parameterization results of $f(\mathrm{RH})$ are presented. Based on the $f(\mathrm{RH})$ measurements, a new algorithm for deriving aerosol hygroscopicity parameter is introduced. An application of the retrieved $\kappa$ in the prediction of the $\mathrm{CCN}$ number concentration $\left(N_{\mathrm{CCN}}\right)$, along with the comparison study of $N_{\mathrm{CCN}}$ between the calculated and in situ measured values, is also performed. These results are of great reference value to the relevant model simulations of aerosol particles in the northern part of the NCP region.

\section{Experiment and instrumentation}

The Wuqing site $\left(39^{\circ} 23^{\prime} \mathrm{N}, 117^{\circ} 01^{\prime} \mathrm{E}, 6 \mathrm{~m}\right.$ a.s.l. $)$ is a suburban observation station in the NCP. It is situated in between the megacities Beijing and Tianjin. Wuqing can highly represent the regional aerosol pollution in the northern part of NCP. More detailed site descriptions can be found in Ran et al. (2011) and Liu et al. (2011). A fog and haze experiment of the HaChi project was carried out at Wuqing from the end of October, 2009 to late January, 2010. The aim of the campaign is to obtain more insight into the physical and chemical characteristics of pollution aerosols, as well as the difference of aerosol optical properties between fog and haze, hence serving as reference criteria for distinguishing fog from haze. This work mainly focuses on the method of deriving $\kappa$ from the measured $f(\mathrm{RH})$ in January in the northern part of the NCP region.

During the entire winter experiment, ground-level aerosol size distribution, optical and activation properties, visibility and meteorological parameters were measured. The PNSD in the submicron size range $(14-736 \mathrm{~nm})$ was measured by a scanning mobility particle sizer (SMPS), with a time resolution of $5 \mathrm{~min}$. A continuous-flow dual CCN counter (CCNC200, DMT, USA) (Roberts and Nenes, 2005; Lance et al., 2006) was utilized to measure the aerosol activation properties at five set supersaturations (nominally 0.07, 0.10, 0.20, 0.40 , and $0.80 \%$ ). The observations were recorded every 30 minutes, and details can be obtained in Deng et al. (2011). The continuous $f(\mathrm{RH})$ measurement with a humidification system took place during 1-20 January 2010. A complete humidification cycle, with both elevated and decreased $\mathrm{RH}$ periods, lasted for about $2.5 \mathrm{~h}$. In the data processing procedure, every $1 \mathrm{~min}$ dry aerosol light scattering and absorption data, visibility, as well as meteorological parameters, were averaged into 5 min mean values.

As introduced before, the two integrating nephelometers operated in parallel are often applied in the measurement of
$f(\mathrm{RH})$. What we used in this work is the integrating nephelometer (TSI Inc., Model 3563) at three wavelengths of 450, 550 and $700 \mathrm{~nm}$, respectively. With no special statement, the wavelength of $550 \mathrm{~nm}$ is chosen for discussion in this study. In the humidification system, one reference nephelometer is used to measure the aerosol light scattering coefficient at dry conditions (usually defined as RH $<40 \%$ ), shortly called as "Dry-NEPH"; the other one, correspondingly named as "Humi-NEPH", is operated in humidified conditions, hence the aerosol light scattering at a given RH is determined. The humidifier in the Humi-NEPH mainly consists of the following two parts. It is comprised of a deionized water bath connected in between the inhaled aerosol sample line and the nephelometer, and a water vapour penetrating membrane tube immerged through a heatable metal pipe. The aerosol flow is first exposed to an increasing $\mathrm{RH}$ in the humidifier till a maximum RH value has been reached inside the Humi$\mathrm{NEPH}$, and then dehydrated with the decrease of RH. The given $\mathrm{RH}$, depending on the flow and surrounding temperature conditions, is achieved by controlling of the water temperature inside the water bath. By modulating the power of the heating equipment, the water temperature is regulated, which in turn controls the water vapour permeated to mix with aerosol sample. During our $f(\mathrm{RH})$ measurements, 117 valid humidifying cycles are achieved. Generally, the humidifier is capable of increasing the RH from 30 to $90 \%$. Nevertheless, cases of RH lower than $20 \%$ and up to $95 \%$ have been occasionally observed. More details of the Humi-NEPH can refer to Covert et al. (1972) and Fierz-Schmidhauser et al. (2010c).

A comparative analysis of $\sigma_{\mathrm{sc}}$ between measured with the Humi-NEPH at RH below $40 \%$ and the reference Dry-NEPH was performed. Results show that the dry $\sigma_{\mathrm{sc}}$ values measured with the two nephelometers generally agree well with each other, with the correlation coefficient higher than 0.99 $(R=0.998)$. The corresponding regression slope and intercept are 1.06 and -0.59 , respectively, suggesting that the dry $\sigma_{\mathrm{sc}}$ measured with the Humi-NEPH is relatively higher. The discrepancies between the two observations could be induced by the following accounts. One is probably due to the weak hygroscopic growth of aerosols at low RH, leading to higher $\sigma_{\mathrm{sc}}$ values than those measured under dry conditions. Another possible explanation may be attributed to a difference in RH or in the RH history of the aerosol sample in the nephelometer system along with hysteresis effects. Additionally, uncertainties of the $\sigma_{\mathrm{sc}}$ measurement derived from different aerosol chemical compositions and mixing states at high aerosol loading can also contribute considerably to the discrepancies.

\section{Results and discussion}

In this section, the characteristics and variations of simultaneously measured $f(\mathrm{RH})$, dry $\sigma_{\mathrm{sc}}$ and wind parameters will 
be investigated first. The parameterization results of $f(\mathrm{RH})$ under different pollution cases are discussed based on the sensitivity analysis on the factors influencing the time variance of $f(\mathrm{RH})$. An algorithm for retrieving the aerosol hygroscopicity parameter with $f(\mathrm{RH})$ measurements is introduced.

\subsection{Overview of the $f(\mathrm{RH})$ measurements}

Previous work has demonstrated that there were two typical synoptic conditions in winter of the NCP region. Strong winds from the north are often observed with the slightest polluted conditions, while the mild southerly winds would result in severe local pollution due to the accumulation of pollutants with weak diffusion, contributing to the highly frequent haze events (Xu et al., 2011). In this sense, aerosol pollution events in winter at Wuqing are highly correlated with the wind speed and prevailing wind direction. To investigate the variation of $f(\mathrm{RH})$ under different pollution levels, two distinctly different aerosol pollution episodes were recognized beforehand.

Figure 1 presents the time series of the 5 min mean dry $\sigma_{\mathrm{sc}}$ at $550 \mathrm{~nm}$ wavelength $\left(\sigma_{\mathrm{sc}, \mathrm{dry}}^{550}\right)$ and the simultaneously measured wind parameter throughout the January observations. Considering the wind dependency of dry $\sigma_{\mathrm{sc}}$, several typical observation periods are selected to categorize the clean and polluted cases. During the periods of DOY4.2-5.6 and DOY11-13.5 (DOY here means the date of the year, counting from number 1. For example DOY1.5 thus represents 12:00 $\mathrm{h}$ of 1 January and so on), the dominating wind is continuous strong northerly, with wind speeds generally reaching above $5 \mathrm{~m} \mathrm{~s}^{-1}$. Most of the accumulated air pollutants are swept away and the Wuqing site is controlled by the clean air mass from the northern regions. The dry $\sigma_{\mathrm{sc}}$ hardly exceeds $100 \mathrm{Mm}^{-1}$. The corresponding 5 min mean dry $\sigma_{\mathrm{sc}}$ for the two periods is $44.7 \pm 21.2 \mathrm{Mm}^{-1}$, being much lower than that of the overall mean level $\left(484.5 \pm 458.1 \mathrm{Mm}^{-1}\right)$ in January. Consequently, the two periods are chosen as the representative of clean conditions. During DOY7-11 and DOY16-20, the wind speed almost keeps fluctuating at around $1 \mathrm{~m} \mathrm{~s}^{-1}$. The campaign site is mainly influenced by the local emissions and pollutants transported from surrounding areas. The dry $\sigma_{\mathrm{sc}}$ over $1000 \mathrm{Mm}^{-1}$ is frequently observed, with a significantly high 5 min mean $\sigma_{\mathrm{sc}}$ value of $894.8 \pm 410.9 \mathrm{Mm}^{-1}$. As a result, these two periods are used to characterize the polluted cases.

Overall, the measured $f(\mathrm{RH})$ varies in the range of 1.0 3.0. Table 1 displays the mean and corresponding standard deviation $(\sigma)$ values of in situ measured $f(\mathrm{RH})$ at specific RHs under different pollution levels, where "Average" represents the overall mean value for the whole $f(\mathrm{RH})$ measurement period. It can be found that $f(\mathrm{RH})$ increases significantly with increasing $\mathrm{RH}$. At $80 \% \mathrm{RH}$, the mean $f(\mathrm{RH})$ values for clean and polluted cases are $1.46 \pm 0.15$ and $1.58 \pm 0.19$, respectively, while the corresponding mean
Table 1. The measured $f(\mathrm{RH})$ at given RHs, along with the simultaneously measured 5 min mean dry $\sigma_{\mathrm{sc}}$, under different pollution levels (mean value \pm standard deviation $(1 \sigma)$ ). "Average" here represents the overall mean value for the whole $f(\mathrm{RH})$ measurement period.

\begin{tabular}{ccccc}
\hline & \multicolumn{3}{c}{$f(\mathrm{RH})$} \\
\cline { 3 - 5 } & & Average & Clean & Polluted \\
\multicolumn{2}{c}{$\sigma_{\text {sc, dry }}\left(\mathrm{Mm}^{-1}\right)$} & $484.5 \pm 458.1$ & $44.7 \pm 21.2$ & $894.8 \pm 410.9$ \\
\hline RH & $50 \% \pm 1 \%$ & $1.08 \pm 0.09$ & $1.03 \pm 0.06$ & $1.12 \pm 0.08$ \\
& $55 \% \pm 1 \%$ & $1.12 \pm 0.09$ & $1.04 \pm 0.07$ & $1.16 \pm 0.06$ \\
$60 \% \pm 1 \%$ & $1.19 \pm 0.13$ & $1.09 \pm 0.06$ & $1.19 \pm 0.11$ \\
$65 \% \pm 1 \%$ & $1.21 \pm 0.15$ & $1.12 \pm 0.10$ & $1.29 \pm 0.13$ \\
$70 \% \pm 1 \%$ & $1.36 \pm 0.15$ & $1.20 \pm 0.09$ & $1.34 \pm 0.11$ \\
$75 \% \pm 1 \%$ & $1.40 \pm 0.17$ & $1.34 \pm 0.15$ & $1.48 \pm 0.14$ \\
$80 \% \pm 1 \%$ & $1.58 \pm 0.22$ & $1.46 \pm 0.15$ & $1.58 \pm 0.19$ \\
$85 \% \pm 1 \%$ & $1.66 \pm 0.23$ & $1.57 \pm 0.16$ & $1.70 \pm 0.24$ \\
$90 \% \pm 1 \%$ & $1.90 \pm 0.27$ & $1.71 \pm 0.26$ & $1.93 \pm 0.21$ \\
\hline
\end{tabular}

$f(\mathrm{RH})$ to the overall average condition is $1.58 \pm 0.22$, approximating to that of the value during polluted periods. The $f(\mathrm{RH}=80 \%)$ measurements presented here are comparable to the results concluded by Pan et al. (2009) at a rural site near Beijing, with the mean $f(\mathrm{RH})$ values of $1.31 \pm 0.03$ and $1.57 \pm 0.02$ corresponding to clean and urban pollution episodes, respectively. These values are all much higher than those reported by Yan et al. (2009) for the Shangdianzi background observation station, another rural site of northern China with smaller anthropogenic influence.

At $\mathrm{RH}=90 \%$, the mean $f(\mathrm{RH})$ for the entire $f(\mathrm{RH})$ observation period is $1.90 \pm 0.27$, while the mean values for both clean and polluted conditions are $1.71 \pm 0.26$ and $1.93 \pm 0.21$, respectively. It is noted that the general mean $f(\mathrm{RH}=90 \%)$ is roughly approaching 2.0 . From the definition of $f(\mathrm{RH})$, it indicates that the integral light scattering of the aerosol population has nearly doubled with respect to the $\sigma_{\mathrm{sc}}$ at dry conditions. As suggested in previous studies, aerosol light scattering approximately contributes $90 \%$ to the total aerosol light extinction, and this proportion would increase with growing RH (Yuan et al., 2006; Cheng et al., 2008; Chen et al., 2012). In other words, aerosol light extinction at $90 \%$ RH would be enhanced approximately twice as much as the corresponding value at dry conditions. According to the Koschmieder theory (Seinfeld and Pandis, 1998), there is an empirical negative correlation between the visibility and light extinction. In this sense, the visibility would therefore be degraded to be half of the level at dry conditions. This is of great instructive significance to the low visibility monitoring and forecast for relevant environmental departments.

Table 1 also presents the mean $f(\mathrm{RH})$ results corresponding to both clean and polluted cases. The $f(\mathrm{RH})$ for clean periods is significantly lower than the corresponding value for polluted episodes at each specific RH. In addition, the overall mean $f(\mathrm{RH})$ for the whole $f(\mathrm{RH})$ observation period is 

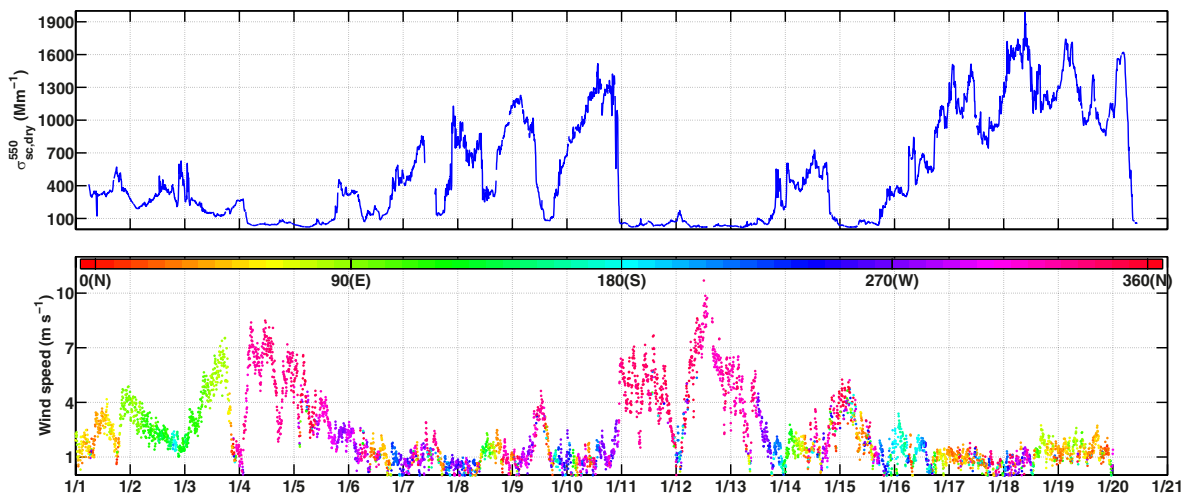

Figure 1. Every $5 \mathrm{~min}$ mean aerosol light scattering coefficients at $550 \mathrm{~nm}$ wavelength $\left(\sigma_{\mathrm{sc} \text {,dry }}^{550}\right)$ under dry conditions, along with the wind parameter during the $f(\mathrm{RH})$ observation periods (coloured dots in the lower panel represent the corresponding wind directions).

even closer to the mean value for polluted cases, as a result of the longer duration of polluted conditions than that of the clean periods. Similar conclusions can be easily drawn from Fig. 2.

Figure 2 illustrates the corresponding variations of mean $f(\mathrm{RH})$ with $\mathrm{RH}$ during the clean, average and polluted periods. The right panel displays the occurrence frequency distributions of measured $f(\mathrm{RH})$ at four selected RHs. It is apparent that $f(\mathrm{RH})$ presents an approximating exponential variation with the increase of $\mathrm{RH}$. The time variance of $f(\mathrm{RH})$ seems to be greater at higher $\mathrm{RH}$, as indicated evidently by the probability distribution function (PDF) of $f(\mathrm{RH})$ in Fig. 2(b). At a specific RH, the $f(\mathrm{RH})$ for polluted episodes is significantly higher than that for clean cases. In particular, the deviation of $f(\mathrm{RH})$ between those measured under clean and polluted conditions is more notable at higher RHs.

The error bar, or rather the standard deviation, of the overall mean $f(\mathrm{RH})$ at a given $\mathrm{RH}$ presents an increasing trend with the increase of RH. The possible reasons for the time variance of $f(\mathrm{RH})$ at different RHs can be attributed as below. As illustrated by the definition of $f(\mathrm{RH})$, it denotes the ratio of aerosol light scattering at a specific RH to dry scattering coefficient. Hence, the time variance of $f(\mathrm{RH})$ is mainly contributed by the variation of $\sigma_{\mathrm{sc}}$ in humidified conditions. According to the theoretical calculation of aerosol optical properties at a fixed wavelength with the Mie model (Mie, 1908; Bohren and Huffman, 1983), the crucial input parameters primarily include the particle size, refractive index and aerosol size distribution. At ambient RH conditions, aerosol hygroscopic growth can change the particle size and refractive index by taking up water, and this effect would be presented more significantly with the increase of RH. Nevertheless, previous investigations have demonstrated that the aerosol refractive index varies slightly with the changing $\mathrm{RH}$, hence has insignificant influence on aerosol light scattering (Lesins et al., 2002; Cheng et al., 2006). Consequently, the key factors dominating the time variance of $f(\mathrm{RH})$ should be ascribed to the aerosol size distribution and hygroscop- icity. In general, at low RH, aerosol hygroscopic growth is not so strong, the accompanied shift of PNSD also indistinct, and thus induces a relatively small time variance of $f(\mathrm{RH})$. While at high $\mathrm{RH}$, the influence of aerosol hygroscopic growth on both of the particle size and PNSD pattern is much more significant. As a result, it will dramatically affect the time variance of $f(\mathrm{RH})$.

Briefly, the $f(\mathrm{RH})$ is determined by both of the PNSD and aerosol hygroscopicity related to the chemical composition. To understand how $f(\mathrm{RH})$ is dependent on the aerosol size distribution and aerosol hygroscopicity, a detailed sensitivity analysis is needed.

\subsection{Factors influencing $f(\mathbf{R H})$}

Detailed procedures of the sensitivity analysis are as follows. (1) With a fixed PNSD, varying the aerosol hygroscopic growth factors, the $f(\mathrm{RH})$ values corresponding to different water uptake abilities can be theoretically estimated with the Mie model. This illustrates how $f(\mathrm{RH})$ depends on aerosol hygroscopicity. Specifically, a mean PNSD is used in this work. (2) Using a constant aerosol hygroscopicity parameter $\kappa$, while altering the PNSD, the $f(\mathrm{RH})$ corresponding to each PNSD can be derived from the Mie calculation. Here we use the temporal averaged size-resolved hygroscopic growth factors. Correspondingly, this is regarded as the sensitivity test of $f(\mathrm{RH})$ to the aerosol size distribution.

To simplify calculations, the sensitivity analysis of $f(\mathrm{RH})$ to the aerosol hygroscopicity is based on the assumption that a specific PNSD corresponds to an integral mean $\kappa$. By changing the value of the overall mean $\kappa$, the mean sizeresolved aerosol hygroscopic growth factors corresponding to different water absorption capabilities can be derived with the $\kappa$-Köhler theory (Petters and Kreidenweis, 2007). Combined with the fixed PNSD, the variation of $f(\mathrm{RH})$ under different hygroscopic capacities can be estimated with the Mie model. 

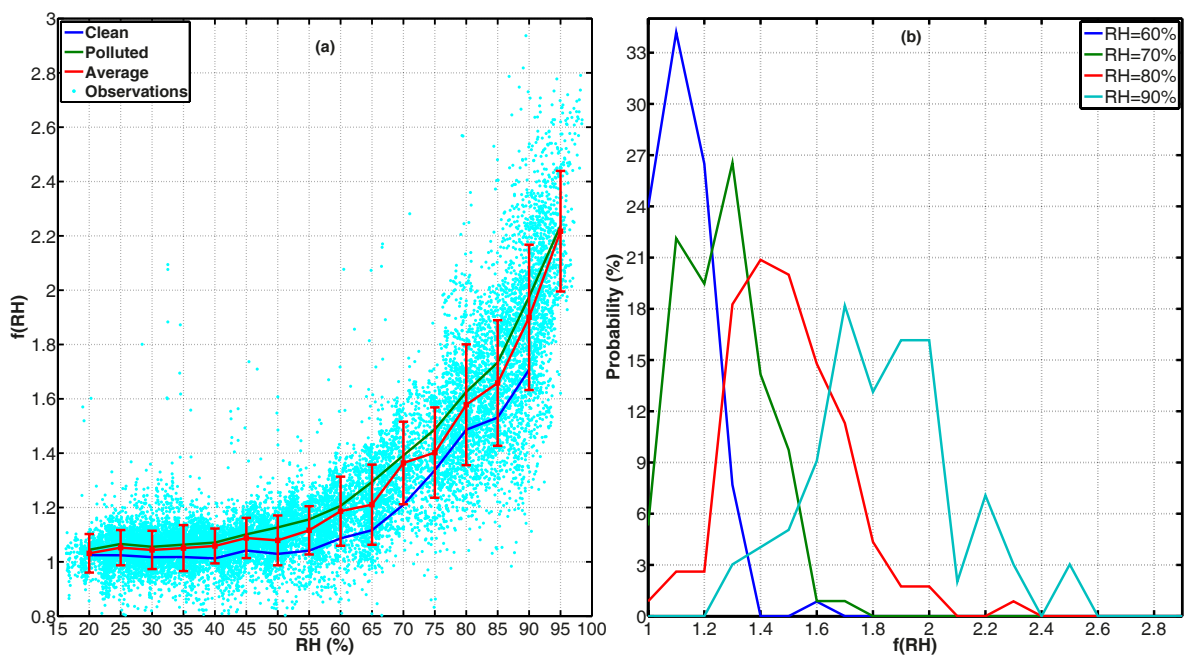

Figure 2. (a) The mean $f(\mathrm{RH})$ under clean, average (mean $\pm 1 \sigma$ ), and polluted conditions. The scattered dots represent the in situ observational results, and lines denote the mean $f(\mathrm{RH})$ values corresponding to different pollution cases. (b) Probability distribution functions (PDFs) of $f(\mathrm{RH})$ at four specific $\mathrm{RHs}(\mathrm{RH}=60,70,80$, and $90 \%$, respectively).

On account of the integrity and availability of the corresponding data for the sensitivity analysis, the in situ measured PNSDs, mean size-resolved hygroscopic growth factors, along with the aerosol optical observations during the HaChi summer campaign are applied in the theoretical calculation of $f(\mathrm{RH})$ with the Mie model. Comprehensive information of the HaChi field campaign and relevant data can be found in previous studies (Liu et al., 2011; Ma et al., 2011; Chen et al., 2012). Results of the sensitivity analysis are given in Fig. 3.

The left panel of Fig. 3 shows the equivalent $f(\mathrm{RH})$ derived from the in situ measured dry $\sigma_{\mathrm{sc}}$ and ambient visibilities. With the visibility observations, the ambient light extinction can be obtained by using the Koschmieder theory (Seinfeld and Pandis, 1998). Based on the single scattering albedo induced by the measurements of light scattering and absorption under dry conditions, the ambient $\sigma_{\mathrm{sc}}$ can then be roughly estimated with the light extinction. In this case, the variation of the achieved $f(\mathrm{RH})$ at a specific $\mathrm{RH}$ (namely $\Delta f(\mathrm{RH})$ ) should be caused by the fluctuation of both PNSD and aerosol hygroscopicity.

The middle panel presents the sensitivity analysis of $f(\mathrm{RH})$ to the aerosol size distribution. The mean sizeresolved hygroscopic growth factors are applied in the Mie calculation. As a result, it can be considered as a constant $\kappa$ to all the measured PNSDs. The $\Delta f(\mathrm{RH})$ in this condition should be mainly induced by the changing PNSD patterns. However, unlike the high perturbation of measured $f(\mathrm{RH})$, little variation of $\Delta f(\mathrm{RH})$ is found in this sensitivity study.

The right panel illustrates the sensitivity results of $f(\mathrm{RH})$ to aerosol hygroscopicity. It can be found that the $f(\mathrm{RH})$ curves are elevated with the increase of the mean $\kappa$ values. That is, at a selected $\mathrm{RH}$, the higher the mean $\kappa$ is, the larger the absolute $f(\mathrm{RH})$ value is. This is even more apparent at high RH conditions.

Generally, the sensitivity analysis demonstrates that, at a specific $\mathrm{RH}$, the $f(\mathrm{RH})$ seems to be more sensitive to the variation of aerosol hygroscopicity. This might be mainly induced by the varying chemical components of aerosol particles. The PNSD pattern changes can also impact the $f(\mathrm{RH})$, and the effect is more significant at high RH conditions.

\subsection{A parameterization scheme of $f(\mathrm{RH})$}

At low $\mathrm{RH}$, the variation of $f(\mathrm{RH})$ is inconspicuous, while under high $\mathrm{RH}$ conditions the $f(\mathrm{RH})$ varies considerably with the increasing RH. To better describe the variation of $f(\mathrm{RH})$, a stepwise function is applied to fit the $f(\mathrm{RH})$ measurements. On the basis of previously suggested empirical functions (Carrico et al., 1998, 2000, 2003; Kotchenruther et al., 1999; Hegg et al., 2002; Randriamiarisoa et al., 2006; Pan et al., 2009), a specific polynomial segment fitting, with the critical $\mathrm{RH}$ of $60 \%$, is applied in the parameterization of $f(\mathrm{RH})$, as (the parameterization results are displayed in Table 2)

$f(\mathrm{RH})=a \times(1-\mathrm{RH})^{-b \times \mathrm{RH}}$.

The fitting parameters of $f(\mathrm{RH})$ are summarized in Table 2 . Large difference of the fitting parameter $b$ appears at $\mathrm{RH}$ below $60 \%$, while the parameterized $f(\mathrm{RH})$ of $\mathrm{RH} \geq 60 \%$ presents slight variation under varying pollution conditions. At low RH, the influence of aerosol hygroscopicity on the $f(\mathrm{RH})$ is indistinct, and the $f(\mathrm{RH})$ could be more sensitive to the changing PNSD. In this sense, the difference of the fitting parameters among different pollution levels is evident. At high $\mathrm{RH}$, the variation of $f(\mathrm{RH})$ is dominated by the influence coming from the aerosol hygroscopicity. Aerosol 

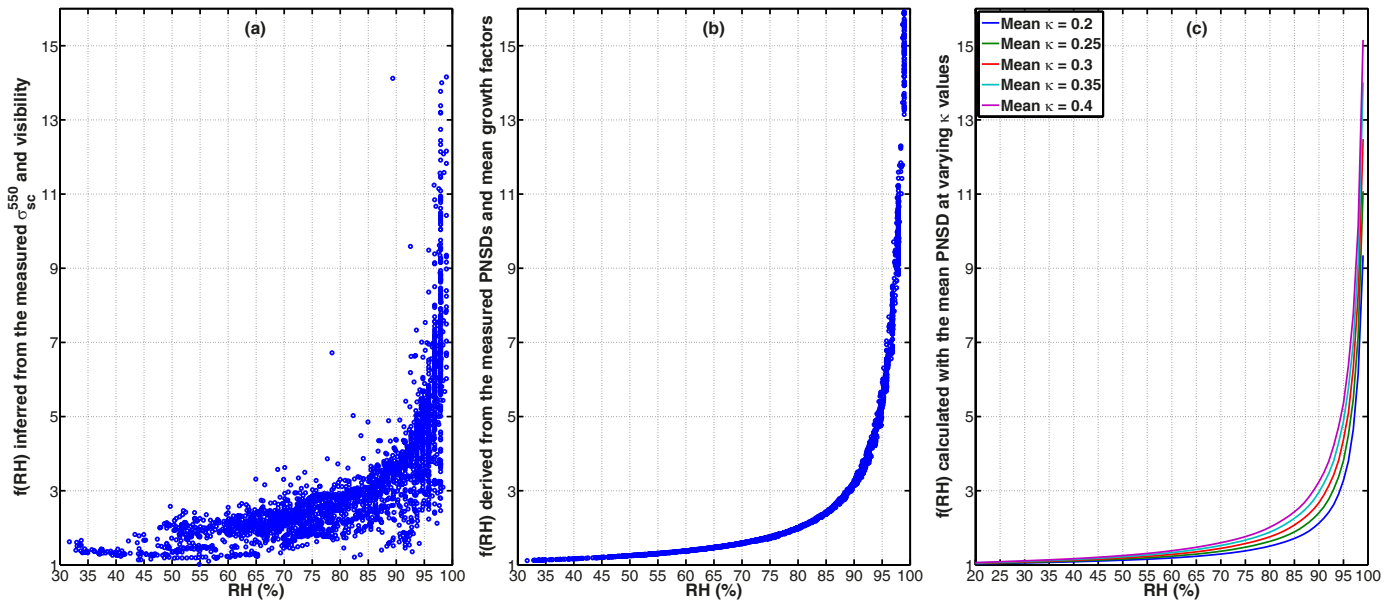

Figure 3. Sensitivity tests of (b) the PNSD and (c) hygroscopicity parameter $\kappa$ to $f(\mathrm{RH})$ based on in situ measured PNSDs and aerosol hygroscopic growth factors during the HaChi summer campaign. The subplot (a) represented the measured $f(\mathrm{RH})$ derived from the in situ observations.

Table 2. The polynomial segment fitting parameter results of $f(\mathrm{RH})$ for different pollution cases $\left(f(\mathrm{RH})=a \times(1-\mathrm{RH})^{-b \times \mathrm{RH}}\right)$.

\begin{tabular}{lcccc}
\hline $\begin{array}{l}\text { RH } \\
\text { ranges }\end{array}$ & $\begin{array}{c}\text { Fitting } \\
\text { parameters }\end{array}$ & $\begin{array}{c}\text { Average } \\
\left(R^{2}=0.81\right)\end{array}$ & $\begin{array}{c}\text { Clean } \\
\left(R^{2}=0.75\right)\end{array}$ & $\begin{array}{c}\text { Polluted } \\
\left(R^{2}=0.84\right)\end{array}$ \\
\hline $\mathrm{RH}<$ & $a$ & $1.02 \pm 0.01$ & $1.00 \pm 0.01$ & $1.03 \pm 0.01$ \\
$60 \%$ & $b$ & $0.21 \pm 0.02$ & $0.10 \pm 0.03$ & $0.26 \pm 0.03$ \\
$\mathrm{RH} \geq$ & $a$ & $1.08 \pm 0.01$ & $1.00 \pm 0.01$ & $1.14 \pm 0.01$ \\
$60 \%$ & $b$ & $0.26 \pm 0.003$ & $0.26 \pm 0.01$ & $0.25 \pm 0.01$ \\
\hline
\end{tabular}

hygroscopicity is mainly determined by the mass fraction of ammonium sulfate or nitrate in the accumulation mode of the aerosol population, with the soluble mass fraction showing little variation (Liu et al., 2014). Hence, the difference of this effect among varying pollution cases is not apparent. As a result, the fitting parameters would present little variation among different pollution levels.

\subsection{Aerosol hygroscopicity parameter derived from the $f(\mathrm{RH})$ measurements}

The RH dependence of light scattering is a widely used parameter for the description of aerosol hygroscopicity. According to the single parameterized $\kappa$-Köhler theory proposed by Petters and Kreidenweis (2007), with a known mean $\kappa$, the size-resolved aerosol diameter growth factors can be roughly estimated. Combining with the aerosol size distribution, the corresponding $f(\mathrm{RH})$ could be calculated with the Mie model. In contrast, the aerosol hygroscopicity parameter $\kappa$ could be theoretically obtained with the $f(\mathrm{RH})$ and PNSD measurements. It should be pointed out that the achieved $\kappa$, derived from the measured $f(\mathrm{RH})$, is slightly different from the size-dependent $\kappa$. The $\kappa$ here represents the overall mean hygroscopicity corresponding to the aerosol size distribution, reflecting the overall ability of the aerosol population to take up water, without the details of size-resolved hygroscopic growth.

Based on the method described previously (Ervens et al., 2007), a straightforward algorithm for deriving $\kappa$ is proposed in this study. The main difference between the two methods is that, rather than varying the mass fraction of the insoluble compound to restrict the aerosol chemical composition in the algorithm introduced by Ervens et al. (2007), the new method is performed by changing the initial value of the assumed $\kappa$. To reduce the possible influence of observational random errors on the estimated results, all the valid $f(\mathrm{RH})$ measurements in the increasing $\mathrm{RH}$ period during a complete humidifying cycle are used to derive the overall mean hygroscopicity parameter, $\kappa$. In particular, the $\kappa$ during the $2.5 \mathrm{~h}$ observation period is supposed to be constant. On the assumption that all the particle size bins are of the same $\kappa$ value, the size-resolved diameter growth factors at a fixed RH can be estimated according to the $\kappa$-Köhler theory.

By using the simultaneously measured mean PNSD during the entire cycle in the Mie calculation, the $f(\mathrm{RH})$ corresponding to each given $\mathrm{RH}$ can thus be obtained with an assumed $\kappa$. By comparing the estimated $f(\mathrm{RH})$ results to the in situ measured ones, a least summation of the deviations between the two $f(\mathrm{RH})$ values at an individual $\mathrm{RH}$ should be reached at a specific $\kappa$. Consequently, the assumed $\kappa$ is regarded as the mean equivalent $\kappa$ of the whole period. The algorithm procedure is illustrated in Fig. 4.

In this algorithm, the refractive index for dry aerosol particles $\left(\tilde{m}_{\text {dry }}\right)$ is assumed on the basis of the observations during the HaChi campaign (Ma et al., 2011), with the mean value of $\tilde{m}_{\text {dry }}=1.55-0.02 i$. Taking the effect of water uptake on the particle refractive index into consideration, the size-resolved refractive index for ambient aerosols after hygroscopic growth $\left(\tilde{m}_{\text {wet }}\left(D_{\text {wet }}\right)\right)$ can be obtained from the 


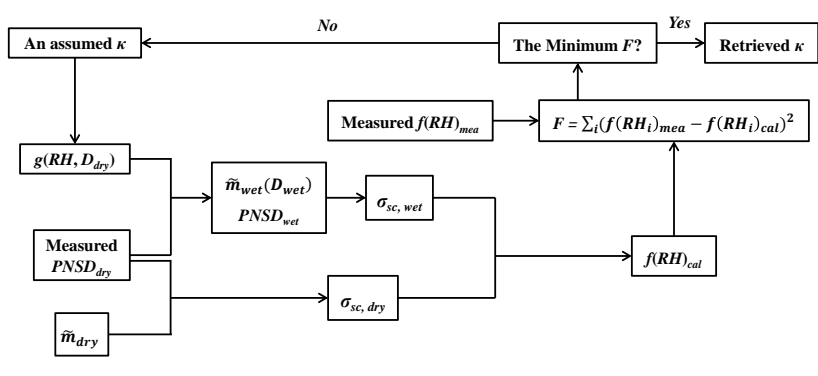

Figure 4. The flow chart of the retrieval algorithm for aerosol hygroscopicity parameter, $\kappa$.

volume-weighted average of the dry particle and water content:

$\tilde{m}_{\text {wet }}\left(D_{\text {wet }}\right)=\frac{\left(g\left(\mathrm{RH}, D_{\text {dry }}\right)^{3}-1\right) \times \tilde{m}_{\text {water }}+\tilde{m}_{\text {dry }}}{g\left(\mathrm{RH}, D_{\text {dry }}\right)^{3}}$

where, $D_{\text {dry }}$ and $D_{\text {wet }}$ are the aerosol diameters at dry and ambient $\mathrm{RH}$ conditions, respectively. $g\left(\mathrm{RH}, D_{\text {dry }}\right)$ represents the size-resolved diameter growth factors. $\tilde{m}_{\text {water }}$ is the refractive index for pure water, which is reported to be 1.33-0i .

Using the relevant aforementioned parameters, the aerosol light scattering coefficients corresponding to both dry and specific RH conditions can be derived with the Mie model. As a result, the $f(\mathrm{RH})$ at a given $\mathrm{RH}$ is determined, expressed as $f(\mathrm{RH})_{\text {cal }}$. Accordingly, all the $f(\mathrm{RH})_{\text {cal }}$ at every individually measured $\mathrm{RH}_{i}$ during the whole humidifying cycle are estimated. After that, a discriminant coefficient, $F$, corresponding to each assumed $\kappa$ is introduced as

$F=\sum_{i}\left(f\left(\mathrm{RH}_{i}\right)_{\mathrm{cal}}-f\left(\mathrm{RH}_{i}\right)_{\text {mea }}\right)^{2}$,

where $f\left(\mathrm{RH}_{i}\right)_{\text {mea }}$ stands for the in situ measured $f(\mathrm{RH})$ at a specific $\mathrm{RH}_{i}$ during the observation period. By varying the initial value of assumed $\kappa$, a minimum $F$ can be achieved. Hence, the mean equivalent $\kappa$ of the entire cycle is obtained.

Figure 5 illustrates an example of the calculated $\kappa$ with the described algorithm. The red circles in the left panel represent the valid $f(\mathrm{RH})$ measurements during a humidifying cycle, while the gradient coloured ones denote the calculated $f(\mathrm{RH})$ corresponding to different assumed $\kappa$ values. Nearly all the $f(\mathrm{RH})$ measurements are distributed in the calculation ranges. Therefore, a specific $\kappa$ should be definitely achieved to satisfy the requirement of minimizing the discriminant coefficient, $F$. The right panel of Fig. 5 just presents the results of discriminant coefficients corresponding to the varying assumed $\kappa$ values shown in the left panel. It can be found that $F$ reaches a minimum level at $\kappa=0.31$, indicating that the mean equivalent $\kappa$ of the selected cycle is 0.31 .

With the estimation algorithm, the equivalent $\kappa$ of all the effective $f(\mathrm{RH})$ measurements are retrieved. Results show that, during the entire $f(\mathrm{RH})$ observation period, the mean
Table 3. Statistical results of the mean hygroscopicity parameter $\kappa$, derived from $f(\mathrm{RH})$ observations ( $n$ denotes the sample size corresponding to each case).

\begin{tabular}{ll|ccc}
\hline \multicolumn{1}{c|}{ Statistics } & $\begin{array}{c}\text { Average } \\
(n=117)\end{array}$ & $\begin{array}{c}\kappa \\
\text { Clean } \\
(n=24)\end{array}$ & $\begin{array}{c}\text { Polluted } \\
(n=50)\end{array}$ \\
\hline Mean & & 0.14 & 0.11 & 0.13 \\
Std & 0.05 & 0.03 & 0.04 \\
Min & & 0.06 & 0.06 & 0.06 \\
Max & & 0.28 & 0.16 & 0.28 \\
Percentile & 5th & 0.07 & 0.06 & 0.09 \\
& 10th & 0.09 & 0.07 & 0.09 \\
& 25th & 0.10 & 0.09 & 0.10 \\
& 50th & 0.13 & 0.11 & 0.14 \\
& 75th & 0.17 & 0.15 & 0.15 \\
& 90th & 0.21 & 0.15 & 0.17 \\
& 95th & 0.25 & 0.16 & 0.21 \\
\hline
\end{tabular}

equivalent $\kappa$ value varies over the range of $0.06-0.28$, with a general mean value of $0.14 \pm 0.05$. The statistical results of the derived mean $\kappa$ corresponding to different pollution cases are also summarized in Table 3.

The statistics of the equivalent $\kappa$ listed in Table 3 reveal that differences among the equivalent $\kappa$ values are commonly found under varying pollution conditions. To be specific, in clean cases as defined beforehand, the mean value of the equivalent $\kappa$ retrieved from the measured $f(\mathrm{RH})$ is $0.11 \pm 0.03$, while the mean value for polluted episodes is relatively higher $(0.13 \pm 0.04)$. One possible reason can be concluded as below. Different aerosol types can result in large variations of the aerosol hygroscopicity, leading to distinct variation of the $f(\mathrm{RH})$. During different pollution periods, the main chemical compositions of aerosol particles could be of great difference, hence the aerosol water uptake ability might differ significantly from each other.

It is noteworthy that uncertainties of the derived equivalent $\kappa$ results are possibly caused by the following two aspects. One stems from the uncertainty of the assumptions applied in the retrieval algorithm. A constant $\kappa$ is assumed during a complete $2.5 \mathrm{~h}$ humidifying cycle, which is generally appropriate for the conditions that chemical composition changes of ambient aerosols are unremarkable. Due to the lack of size-resolved aerosol hygroscopic growth factors, a constant $\kappa$ is assumed for all the particle size bins to calculate the equivalent $\kappa$. This is apparently not in accordance with the actual conditions. Results show that the $\kappa$ values corresponding to different particle sizes are of distinct variation (Chen et al., 2012). In addition, for particles of a specific size, the varying aerosol chemical composition, mixing state and particle morphology could also result in a relatively wider probability distribution of $\kappa$ (Liu et al., 2011). The other uncertainty lies in the observation errors of the data used in the calculation of $\kappa$. In other words, all the observation parameters, 

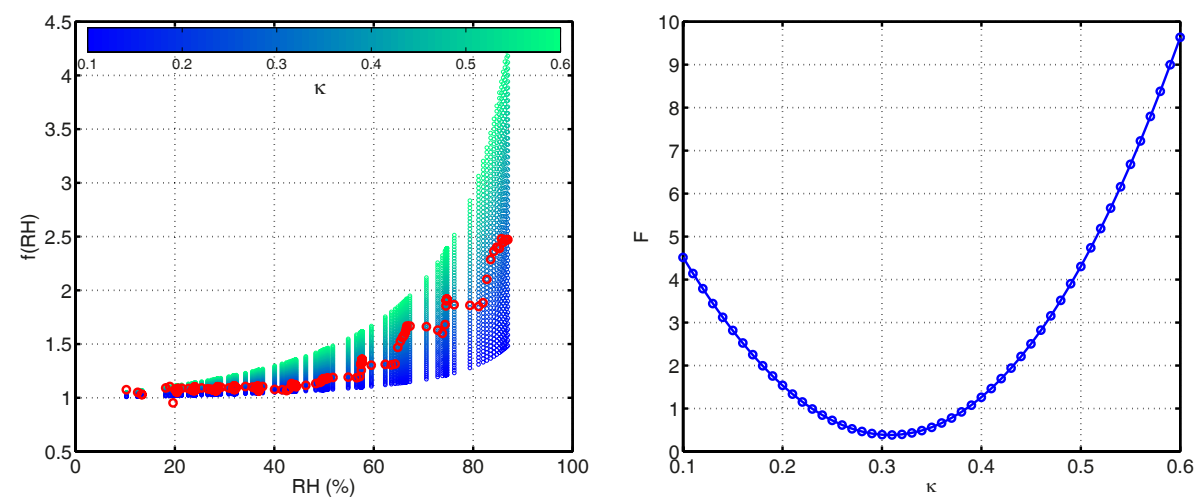

Figure 5. One case of the calculated $\kappa$. In the left panel, the red circles stand for the valid $f(\mathrm{RH})$ observations during a humidifying cycle, while the gradient coloured ones represent the corresponding $f(\mathrm{RH})$ calculated with an assumed specific $\kappa$. The right panel shows the discriminant coefficient, $F$, corresponding to each assumed $\kappa$.

including the in situ measured $f(\mathrm{RH})$, PNSDs, $\sigma_{\mathrm{sc}}$ at both dry and humidified conditions, along with the RH observations, are of different uncertainties. It would inevitably lead to random error of the derived $\kappa$.

\subsection{An application: prediction of $\mathrm{CCN}$ number concentration}

Combining the derived $\kappa$ values, the number concentration of $\mathrm{CCN}$ is calculated with the $f(\mathrm{RH})$ and PNSD measurements. A comparison of the predicted and in situ measured $\mathrm{CCN}$ number concentrations is performed in this section.

According to the $\kappa$-Köhler theory (Petters and Kreidenweis, 2007), the critical activation dry diameter, $D_{\mathrm{c}}$, at a specific supersaturation (SS) can be theoretically derived with a known $\kappa$. That is, at the given SS, particles equal to or larger than $D_{\mathrm{c}}$ can be activated into CCN, while the aerosols smaller than $D_{\mathrm{c}}$ cannot be activated. Consequently, the number of activated CCN, namely $N_{\mathrm{CCN}}$, at a selected SS can be calculated as follows:

$N_{\mathrm{CCN}}=\int_{D_{\mathrm{c}}}^{\infty} n(\log D) \times \mathrm{AR}(D) \times \mathrm{d} \log D$,

where $D$ is the dry particle diameter, $n(\log D)$ stands for the in situ measured PNSD and $\operatorname{AR}(D)$ represents the activation ratio, namely the number fraction of the activated aerosols to the aerosol population.

During the winter fog and haze experiment, the PNSD measurements are only in the size range of $14-736 \mathrm{~nm}$, lacking the size distribution information of larger aerosols in super micron ranges. Nevertheless, the mean level of the total number concentration of particles larger than $700 \mathrm{~nm}$ is just $13 \mathrm{~cm}^{-3}$ during the $2009 \mathrm{HaChi}$ winter campaign (Ma et al., 2011). As a result, without considering some special pollution episodes, e.g. dust storms, the slight influence on the $N_{\mathrm{CCN}}$ calculation contributed by the super micron particles could be neglected in this study.
Throughout the $f(\mathrm{RH})$ observations, continuous measurements of the $N_{\mathrm{CCN}}$ at five specific supersaturations $(0.07$, $0.10,0.20,0.40$, and $0.80 \%$ ) are simultaneously conducted. With the observed PNSDs and the real-time $\kappa$ values retrieved from the $f(\mathrm{RH})$ measurements, the corresponding $N_{\mathrm{CCN}}$ at each individual SS can be estimated with Eq. (4). The predicted $N_{\mathrm{CCN}}$ values are then compared to the in situ measured ones at a specific SS, with the comparison results presented in Fig. 6.

Distinctly, at the five supersaturations, the estimation values are generally comparable with the corresponding measured $N_{\mathrm{CCN}}$. At $0.07 \%$ and $0.10 \% \mathrm{SS}$, the calculated $N_{\mathrm{CCN}}$ are significantly lower than the in situ observations, while at SS above $0.20 \%$, with the increase of $N_{\mathrm{CCN}}$, the predictions are evidently higher than the measured $N_{\mathrm{CCN}}$. This is mainly caused by the influence of high $N_{\mathrm{CCN}}$ on the CCNC measurement. That is, at high $N_{\mathrm{CCN}}$, the overlap of particles can result in an underestimation of the actual $N_{\mathrm{CCN}}$. The limited water vapour supply in the cloud chamber of the CCNC instrument could also lead to an underestimation of the measured $N_{\mathrm{CCN}}$ at high $N_{\mathrm{CCN}}$ conditions. Due to the insufficient water vapour supply, a portion of the aerosols that should have been activated would not be activated into CCNs. Determined by the measurement limitations of the CCNC itself, this is much more difficult to maintain at a stable lower supersaturation (SS $<0.1 \%$ ). Consequently, the fluctuation of the supersaturation during the $N_{\mathrm{CCN}}$ measurement would contribute large uncertainty to the observations, leading to different comparison results at varying supersaturations.

To quantitatively evaluate the deviation of $N_{\mathrm{CCN}}$ between the predicted and measured values, a linear regression is performed to all the $N_{\mathrm{CCN}}$ measurements. The fitting function is

$N_{\mathrm{CCN}, \text { cal }}=b \times N_{\mathrm{CCN} \text {, mea }}$.

Considering the underestimation of $N_{\mathrm{CCN}}$ induced by high $N_{\mathrm{CCN}}$, a similar influence would not appear at relatively low 

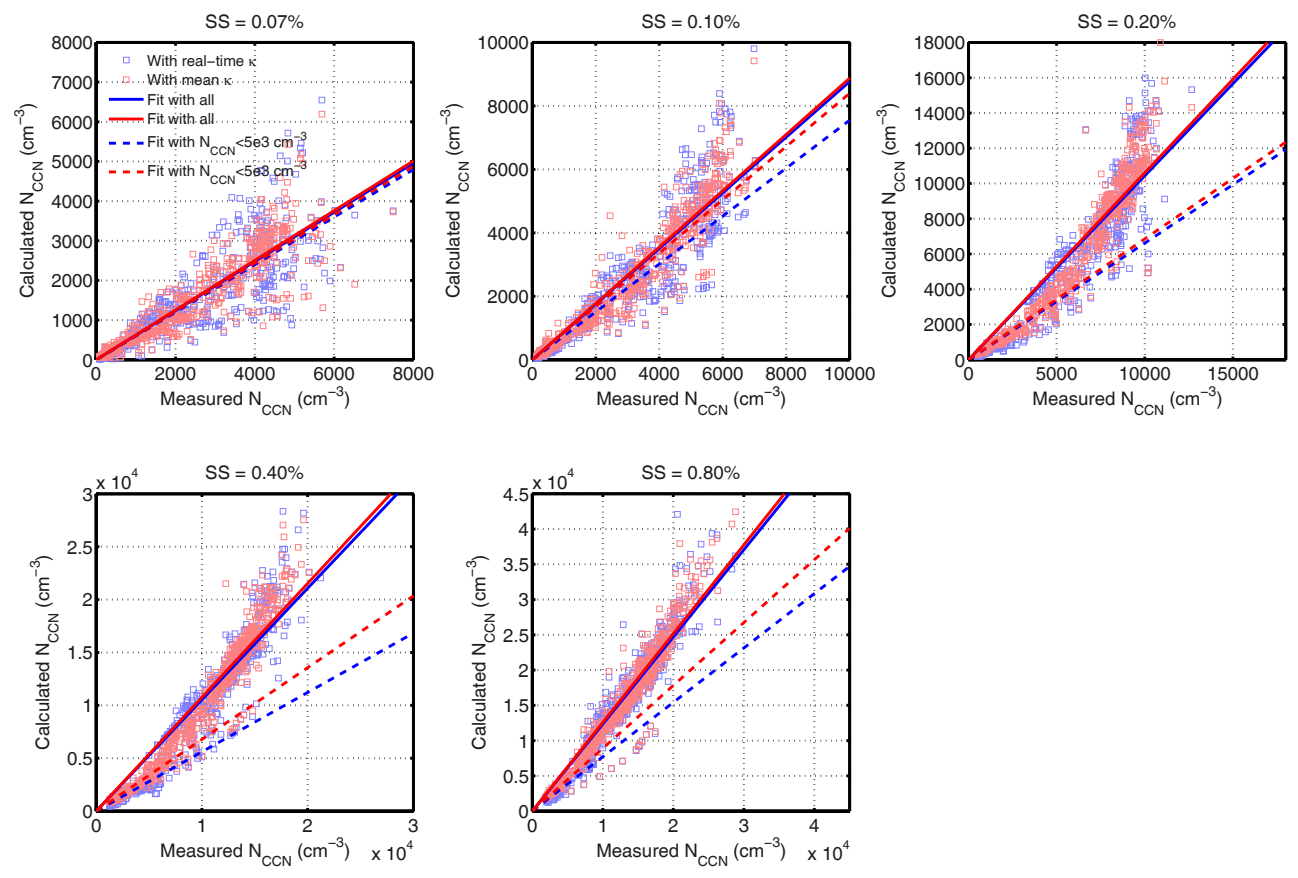

Figure 6. Comparison between in situ measured $N_{\mathrm{CCN}}$ and calculated $N_{\mathrm{CCN}}$ at five specific supersaturations. Blue squares represent the estimated $N_{\mathrm{CCN}}$ with the real-time $\kappa$, while the red ones denote the estimation results with the overall mean $\kappa$ during the entire $f(\mathrm{RH})$ measurements. The blue and red solid lines stand for the fitting results of all the $N_{\mathrm{CCN}}$ samples corresponding to the two kinds of $\kappa$, respectively; while the blue and red dashed lines are the fitting results in the case of measured $N_{\mathrm{CCN}}<5000 \mathrm{~cm}^{-3}$.

$\mathrm{CCN}$ number concentrations of $N_{\mathrm{CCN}}<5000 \mathrm{~cm}^{-3}$. Hence, the linear fitting is carried out for the following two conditions. One is aimed at all the $N_{\mathrm{CCN}}$ measurements. The other is just to focus on the cases of $N_{\mathrm{CCN}}$ below $5000 \mathrm{~cm}^{-3}$. The corresponding fitting results at each specific SS are summarized in Table 4 . The fitting parameters displayed are the slope of the regression line, $b$, and the corresponding regression sum of squares, $R^{2}$, respectively.

Apart from the relatively lower $R^{2}$ of 0.74 at $0.07 \% \mathrm{SS}$, the $R^{2}$ values at the other four supersaturations are all higher than 0.8 , suggesting a good correlation between the calculated $N_{\mathrm{CCN}}$ and measured ones. On account of the increase of $N_{\mathrm{CCN}}$ with the increasing SS, the fitting slope, $b$, of all the $N_{\mathrm{CCN}}$ samples also presents an evident increasing trend with the increase of SS. To be specific, $b$ has increased from 0.62 at $0.07 \%$ SS to 1.24 at $0.80 \%$ SS, while in the case of $N_{\mathrm{CCN}}<5000 \mathrm{~cm}^{-3}$, the slope $b$ shows no significant variation with the increasing SS, generally fluctuating around 0.7 . This reveals that, excluding the measurement error of the CCNC itself, the predicted $N_{\mathrm{CCN}}$ with the retrieved real-time $\kappa$ is about $30 \%$ lower than the measured values at a specific SS. The $30 \%$ deviation is even lower than the measurement error stemmed from the influence of high $N_{\mathrm{CCN}}$. This partially confirms that the real-time equivalent $\kappa$ retrieved from the $f(\mathrm{RH})$ measurements could well characterize the overall hygroscopic and activation properties of the aerosol population. Besides the real-time $\kappa$, can the temporal averaged equivalent $\kappa$ reliably represent the aerosol hygroscopic and activation features as well? To find some clue for this, the overall mean $\kappa(\kappa=0.14)$ over the whole $f(\mathrm{RH})$ observation period is applied in the analogous calculation of $N_{\mathrm{CCN}}$, and similar comparison and fitting of $N_{\mathrm{CCN}}$ between the predicted and measured results is conducted. The corresponding regression results are also displayed in Table 4.

In the case of $N_{\mathrm{CCN}}$ calculation with the overall mean $\kappa$, the regression slope, $b$, is exclusively higher than that calculated with the real-time $\kappa$ at each individual SS. The corresponding $R^{2}$ values for the overall mean $\kappa$ cases are also significantly higher. This is more obviously presented in the fitting results for the situation of $N_{\mathrm{CCN}}<5000 \mathrm{~cm}^{-3}$, where the slope is closer to 1.0, suggesting less deviation between the estimated and measured values. This demonstrates that the prediction of $N_{\mathrm{CCN}}$ with the overall mean $\kappa$ is more effective than that calculated with the real-time equivalent $\kappa$.

The possible reasons can be concluded as follows. Previous studies have indicated that the aerosol activation property is slightly influenced by the natural variation of aerosol chemical compositions (Deng et al., 2011), while the size effect on the activation ability is dominating (Dusek et al., 2006). The influence of the PNSD on the $N_{\mathrm{CCN}}$ prediction is superior to that of the aerosol hygroscopicity. Moreover, calculation error inevitably lies in the estimation of $N_{\mathrm{CCN}}$. As illustrated in Sect. 3.4, the proposed $\kappa$ retrieval algorithm based on the $f(\mathrm{RH})$ and PNSD measurements would lead 
Table 4. Fitting parameters of the linear regression results in Fig. 6.

\begin{tabular}{ccc|cc|cc|cc}
\hline & \multicolumn{4}{c|}{ Real-time $\kappa$} & \multicolumn{4}{c}{ Overall mean $\kappa$} \\
\cline { 2 - 9 } SS & \multicolumn{2}{c|}{ All } & \multicolumn{2}{|c|}{$N_{\mathrm{CCN}}<5000 \mathrm{~cm}^{-3}$} & \multicolumn{2}{|c|}{ All } & \multicolumn{2}{c}{$N_{\mathrm{CCN}}<5000 \mathrm{~cm}^{-3}$} \\
& $b$ & $R^{2}$ & $b$ & $R^{2}$ & $b$ & $R^{2}$ & $b$ & $R^{2}$ \\
\hline $0.07 \%$ & 0.62 & 0.74 & 0.60 & 0.75 & 0.63 & 0.82 & 0.61 & 0.84 \\
$0.10 \%$ & 0.88 & 0.84 & 0.76 & 0.88 & 0.89 & 0.90 & 0.84 & 0.90 \\
$0.20 \%$ & 1.04 & 0.84 & 0.66 & 0.82 & 1.06 & 0.88 & 0.69 & 0.90 \\
$0.40 \%$ & 1.05 & 0.87 & 0.56 & 0.80 & 1.08 & 0.90 & 0.68 & 0.88 \\
$0.80 \%$ & 1.24 & 0.90 & 0.77 & 0.51 & 1.26 & 0.91 & 0.89 & 0.50 \\
\hline
\end{tabular}

to random error of the derived $\kappa$ and hence result in uncertainty in the calculated final $N_{\mathrm{CCN}}$. However, with the overall mean $\kappa$, the random error of $\kappa$ can be reduced by the temporal averaging method to some extent. As a result, the random deviation of the predicted $N_{\mathrm{CCN}}$ would be decreased, leading to a better correlation with the measured values.

At $N_{\mathrm{CCN}}<5000 \mathrm{~cm}^{-3}$, the slope $b$ for each specific SS is still lower than 0.9 , with the minimum value of 0.61 , even if calculated with the overall mean $\kappa$. The systematic deviation between the predicted and measured results could be attributed to the following accounts. As discussed beforehand, the assumption of a constant $\kappa$ for all the particle size bins applied in the $\kappa$ retrieval algorithm is of unavoidable uncertainty and would also result in uncertainty of the derived $\kappa$. As a consequence, the prediction of $N_{\mathrm{CCN}}$ based on the assumed constant $\kappa$ in the whole size range would certainly possess some calculation error. Another possible explanation can be ascribed to the influence introduced by particles larger than $700 \mathrm{~nm}$. By only considering the PNSDs of submicron particles, the contribution of super micron aerosols to the $N_{\mathrm{CCN}}$ calculation has been neglected. It might also cause uncertainty to the estimation results.

To sum up, taking into consideration of the measurement errors, along with the uncertainty of the predefined assumptions in the $\kappa$ retrieval process with the measured $f(\mathrm{RH})$, the time-averaged mean $\kappa$ over a relatively long observation period is recommended to perform the $N_{\mathrm{CCN}}$ calculation. Alternatively, the retrieved real-time $\kappa$ can be categorized into several types according to a certain classification criterion. Combined with the mean $\kappa$ to different conditions, the in situ measured PNSDs can be used to predict $N_{\mathrm{CCN}}$. In this sense, the retrieval algorithm for $\kappa$ with the $f(\mathrm{RH})$ measurements is of essential importance to the estimation of $N_{\mathrm{CCN}}$. Nevertheless, more efforts need to be taken for the improvement of $f(\mathrm{RH})$ measurements, and thus achieve the goal of lower observation uncertainty but higher temporal resolution.

\section{Summary and conclusions}

The RH dependence of aerosol optical properties, e.g. light scattering, is a crucial input parameter for accurate esti- mation of the direct radiative forcing by aerosols. However, the information of aerosol hygroscopicity is always insufficiently implemented in climate models. As a result, more detailed description and parameterization of hygroscopic growth factors are greatly in need. On this account, measurements of the aerosol light scattering enhancement factor, $f(\mathrm{RH})$, were carried out during the HaChi campaign at the Wuqing site in the northern part of the NCP region. Simultaneously, ground-level PNSD, aerosol optical properties, along with the meteorological parameters, were continuously measured.

Based on the in situ observations, the variation of $f(\mathrm{RH})$ corresponding to different pollution cases is discussed. The sensitivity of $f(\mathrm{RH})$ to both aerosol hygroscopicity and PNSD is investigated with the Mie model. A parameterization of $f(\mathrm{RH})$ for different pollution cases is also performed in this work. Additionally, an improved algorithm for retrieving the aerosol hygroscopicity parameter, $\kappa$, with the $f(\mathrm{RH})$ and PNSD measurements is developed. With the derived equivalent $\kappa$ results, the prediction of $N_{\mathrm{CCN}}$ at five specific supersaturations is separately conducted by using the measured PNSDs. To quantitatively evaluate the estimation results, the predicted $N_{\mathrm{CCN}}$ values are compared to the measured $N_{\mathrm{CCN}}$.

Measurements show that $f(\mathrm{RH})$ increases dramatically with the increasing $\mathrm{RH}$. At $80 \% \mathrm{RH}$, the mean $f(\mathrm{RH})$ for the entire $f(\mathrm{RH})$ observation period is $1.58 \pm 0.22$, while the corresponding mean values for clean and polluted cases are $1.46 \pm 0.15$ and $1.58 \pm 0.19$, respectively. The $f(\mathrm{RH})$ for polluted cases is higher than that for clean episodes at each individual RH. With the increase of RH, the discrepancy of $f(\mathrm{RH})$ is more evident. A sensitivity analysis on the $f(\mathrm{RH})$ influencing factors indicates that, at a specific RH, the measured $f(\mathrm{RH})$ is more significantly influenced by the variation of aerosol hygroscopicity determined by its chemical compositions rather than the aerosol size distribution. A parameterization scheme of $f(\mathrm{RH})$ is achieved with a polynomial segment fitting based on the statistical analysis of the $f(\mathrm{RH})$ measurements. Fitting parameters among different pollution levels would present more distinct deviation at $\mathrm{RH}$ lower than $60 \%$, associated with the stronger influence of the changing PNSD on $f(\mathrm{RH})$. At $\mathrm{RH} \geq 60 \%$, aerosol hygroscopicity is 
the predominant factor leading to the varying $f(\mathrm{RH})$. Liu et al. (2014) have indicated that little variation is presented in the soluble mass fraction in the accumulation mode. As a consequence, it would result in unapparent varying aerosol hygroscopicity and hence insignificant difference of the fitting parameters among different pollution levels.

A straightforward retrieval method of $\kappa$ by using the measured $f(\mathrm{RH})$ and PNSDs is proposed with the assumption that the aerosol hygroscopicity parameter is constant during a complete $2.5 \mathrm{~h}$ humidifying cycle. The derived mean equivalent $\kappa$ is in the range of $0.06-0.28$, with an overall mean value of $0.14 \pm 0.05$. The mean level of calculated equivalent $\kappa$ for clean cases $(0.11 \pm 0.03)$ is much lower than that of pollution episodes $(0.13 \pm 0.04)$.

As an application, the calculated $\kappa$ is used to predict $\mathrm{CCN}$ number concentration. The comparison between the calculated CCN number concentration and in situ measured results reveals a good agreement at each specific supersaturation, especially at high supersaturation conditions. This shows that the proposed $\kappa$ retrieval algorithm with the $f(\mathrm{RH})$ measurements is reasonable and robust.

Acknowledgements. This work is supported by the National 973 project of China (2011CB403402), the National Natural Science Foundation of China under Grant No. 41375134, the Beijing Natural Science Foundation (8131003) and the Beijing Municipal Science and Technology plan project (Z131100006113013).

Edited by: $\mathrm{H} . \mathrm{Su}$

\section{References}

Bohren, C. F. and Huffman, D. R.: Absorption and Scattering of Light by Small Particles, John Wiley, Hoboken, 477-482, 1983.

Carrico, C., Rood, M., and Ogren, J.: Aerosol light scattering properties at Cape Grim, Tasmania, during the first Aerosol Characterization Experiment (ACE 1), J. Geophys. Res., 103, 1656516574, doi:10.1029/98JD00685, 1998.

Carrico, C., Rood, M., Ogren, J., Neusüß, C., Wiedensohler, A., and Heintzenberg, J.: Aerosol optical properties at Sagres, Portugal, during ACE-2, Tellus B, 52, 694-715, doi:10.1034/j.16000889.2000.00049.x, 2000.

Carrico, C., Kus, P., Rood, M., Quinn, P., and Bates, T.: Mixtures of pollution, dust, sea salt, and volcanic aerosol during ACE-Asia: Radiative properties as a function of relative humidity, J. Geophys. Res., 108, 8650, doi:10.1029/2003JD003405, 2003.

Charlson, R. J., Schwartz, S. E., Hales, J. M., Cess, R. D., Coakley Jr., J. A., Hansen, J. E., and Hofmann, D. J.: Climate forcing by anthropogenic aerosols, Science, 255, 423-430, 1992.

Cheng, Y. F., Eichler, H., Wiedensohler, A., Heintzenberg, J., Zhang, Y. H., Hu, M., Herrmann, H., Zeng, L. M., Liu, S., Gnauk, T., Brüggemann, E., and He, L. Y.: Mixing state of elemental carbon and non-light-absorbing aerosol components derived from in situ particle optical properties at Xinken in Pearl River Delta of China, J. Geophys. Res., 111, D20204, doi:10.1029/2005JD006929, 2006.
Cheng, Y. F., Wiedensohler, A., Eichler, H., Su, H., Gnauk, T., Brüggemann, E., Herrmann, H., Heintzenberg, J., Slanina, J., Tuch, T., Hu, M., and Zhang, Y. H.: Aerosol optical properties and related chemical apportionment at Xinken in Pearl River Delta of China, Atmos. Environ., 42, 6351-6372, 2008.

Chen, J., Zhao, C. S., Ma, N., Liu, P. F., Göbel, T., Hallbauer, E., Deng, Z. Z., Ran, L., Xu, W. Y., Liang, Z., Liu, H. J., Yan, P., Zhou, X. J., and Wiedensohler, A.: A parameterization of low visibilities for hazy days in the North China Plain, Atmos. Chem. Phys., 12, 4935-4950, doi:10.5194/acp-12-4935-2012, 2012.

Covert, D. S., Charlson, R. J., and Ahlquist, N. C.: A study of the relationship of chemical composition and humidity to light scattering by aerosols, J. Appl. Meteorol., 11, 968-976, 1972.

Deng, Z. Z., Zhao, C. S., Ma, N., Liu, P. F., Ran, L., Xu, W. Y., Chen, J., Liang, Z., Liang, S., Huang, M. Y., Ma, X. C., Zhang, Q., Quan, J. N., Yan, P., Henning, S., Mildenberger, K., Sommerhage, E., Schäfer, M., Stratmann, F., and Wiedensohler, A.: Size-resolved and bulk activation properties of aerosols in the North China Plain, Atmos. Chem. Phys., 11, 3835-3846, doi:10.5194/acp-11-3835-2011, 2011.

Dusek, U., Frank, G. P., Hildebrandt, L., Curtius, J., Schneider, J., Walter, S., Chand, D., Drewnick, F., Hings, S., Jung, D., Borrmann, S., and Andreae, M. O.: Size matters more than chemistry for cloud-nucleating ability of aerosol particles, Science, 312, 1375-1378, 2006.

Ervens, B., Cubison, M., Andrews, E., Feingold, G., Ogren, J. A., Jimenez, J. L., DeCarlo, P., and Nenes, A.: Prediction of cloud condensation nucleus number concentration using measurements of aerosol size distributions and composition and light scattering enhancement due to humidity, J. Geophys. Res., 112, D10S32, doi:10.1029/2006JD007426, 2007.

Fierz-Schmidhauser, R., Zieger, P., Gysel, M., Kammermann, L., DeCarlo, P. F., Baltensperger, U., and Weingartner, E.: Measured and predicted aerosol light scattering enhancement factors at the high alpine site Jungfraujoch, Atmos. Chem. Phys., 10, 23192333, doi:10.5194/acp-10-2319-2010, 2010a.

Fierz-Schmidhauser, R., Zieger, P., Vaishya, A., Monahan, C., Bialek, J., O’Dowd, C. D., Jennings, S. G., Baltensperger, U., and Weingartner, E.: Light scattering enhancement factors in the marine boundary layer (Mace Head, Ireland), J. Geophys. Res., 115, D20204, doi:10.1029/2009jd013755, 2010 b.

Fierz-Schmidhauser, R., Zieger, P., Wehrle, G., Jefferson, A., Ogren, J. A., Baltensperger, U., and Weingartner, E.: Measurement of relative humidity dependent light scattering of aerosols, Atmos. Meas. Tech., 3, 39-50, doi:10.5194/amt-3-392010, 2010c.

Fitzgerald, J., Hoppel, W., and Vietti, M.: The size and scattering coefficient of urban aerosol particles at Washington, DC as a function of relative humidity, J. Atmos. Sci., 39, 1838-1852, 1982.

Gasso, S., Hegg, D., Covert, D., Collins, D., Noone, K., Öström, E., Schmid, B., Russell, P., Livingston, J., Durkee, P., and Jonsson, H.: Influence of humidity on the aerosol scattering coefficient and its effect on the upwelling radiance during ACE-2, Tellus B, 52, 546-567, 2000.

Hegg, D. A., Covert, D. S., Crahan, K., and Jonssen, H.: The dependence of aerosol light-scattering on RH over the Pacific Ocean, Geophys. Res. Lett., 29, 1219, doi:10.1029/2001GL014495, 2002. 
IPCC: Climate Change 2007 - The Physical Science Basis, edited by: Solomon, S., Cambridge Univ. Press, New York, 2007.

Khalizov, A. F., Xue, H., Wang, L., Zheng, J., and Zhang, R.: Enhanced Light Absorption and Scattering by Carbon Soot Aerosol Internally Mixed with Sulfuric Acid, J. Phys. Chem. A, 113, 1066-1074, 2009.

Kim, J., Yoon, S.-C., Jefferson, A., and Kim, S.-W.: Aerosol hygroscopic properties during Asian dust, pollution, and biomass burning episodes at Gosan, Korea, in April 2001, Atmos. Environ., 40, 1550-1560, 2006.

Kotchenruther, R. and Hobbs, P.: Humidification factors of aerosols from biomass burning in Brazil, J. Geophys. Res., 103, 3208132089, doi:10.1029/98JD00340, 1998.

Kotchenruther, R. A., Hobbs, P. V., and Hegg, D. A.: Humidification factors for atmospheric aerosols off the mid-Atlantic coast of the United States. J. Geophys. Res., 104, 2239-2251, 1999.

Lance, S., Medina, J., Smith, J. N., and Nenes, A.: Mapping the operation of the dmt continuous flow CCN counter, Aerosol Sci. Tech., 40, 242-254, 2006.

Lesins, G., Chylek, P., and Lohman, U.: A study of internal and external mixing scenarios and its effect on aerosol optical properties and direct radiative forcing, J. Geophys. Res., 107, 4094, doi:10.1029/2001JD000973, 2002.

Li-Jones, X., Maring, H., and Prospero, J.: Effect of relative humidity on light scattering by mineral dust aerosol as measured in the marine boundary layer over the tropical Atlantic Ocean, J. Geophys. Res., 103, 31113-31121, doi:10.1029/98JD01800, 1998.

Liu, H. J., Zhao, C. S., Nekat, B., Ma, N., Wiedensohler, A., van Pinxteren, D., Spindler, G., Müller, K., and Herrmann, H.: Aerosol hygroscopicity derived from size-segregated chemical composition and its parameterization in the North China Plain, Atmos. Chem. Phys., 14, 2525-2539, doi:10.5194/acp-14-25252014, 2014.

Liu, P., Zhao, C., Zhang, Q., Deng, Z., Huang, M., Ma, X., and Tie, X.: Aircraft study of aerosol vertical distributions over Beijing and their optical properties, Tellus B, 61, 756-767, 2009.

Liu, P. F., Zhao, C. S., Göbel, T., Hallbauer, E., Nowak, A., Ran, L., Xu, W. Y., Deng, Z. Z., Ma, N., Mildenberger, K., Henning, S., Stratmann, F., and Wiedensohler, A.: Hygroscopic properties of aerosol particles at high relative humidity and their diurnal variations in the North China Plain, Atmos. Chem. Phys., 11, 3479-3494, doi:10.5194/acp-11-3479-2011, 2011.

Malm, W. C. and Day, D. E.: Estimates of aerosol species scattering characteristics as a function of relative humidity, Atmos. Environ., 35, 2845-2860, doi:10.1016/s1352-2310(01)00077-2, 2001.

Malm, W. C., Day, D. E., Kreidenweis, S. M., Collett, J. L., and Lee, T.: Humidity-dependent optical properties of fine particles during the big bend regional aerosol and visibility observational study, J. Geophys. Res., 108, 4279, doi:10.1029/2002jd002998, 2003.

Ma, N., Zhao, C. S., Nowak, A., Müller, T., Pfeifer, S., Cheng, Y. F., Deng, Z. Z., Liu, P. F., Xu, W. Y., Ran, L., Yan, P., Göbel, T., Hallbauer, E., Mildenberger, K., Henning, S., Yu, J., Chen, L. L., Zhou, X. J., Stratmann, F., and Wiedensohler, A.: Aerosol optical properties in the North China Plain during HaChi campaign: an in-situ optical closure study, Atmos. Chem. Phys., 11, 5959-5973, doi:10.5194/acp-11-5959-2011, 2011.
Massling, A., Stock, M., Wehner, B., Wu, Z. J., Hu, M., Brüggemann, E., Gnauk, T., Herrmann, H., and Wiedensohler, A.: Size segregated water uptake of the urban submicrometer aerosol in Beijing, Atmos. Environ., 43, 1578-1589, 2009.

McInnes, L., Bergin, M., Ogren, J., and Schwartz, S.: Apportionment of light scattering and hygroscopic growth to aerosol composition, Geophys. Res. Lett., 25, 513-516, doi:10.1029/98GL00127, 1998.

Meier, J., Wehner, B., Massling, A., Birmili, W., Nowak, A., Gnauk, T., Brüggemann, E., Herrmann, H., Min, H., and Wiedensohler, A.: Hygroscopic growth of urban aerosol particles in Beijing (China) during wintertime: a comparison of three experimental methods, Atmos. Chem. Phys., 9, 6865-6880, doi:10.5194/acp9-6865-2009, 2009.

Mie, G.: Beiträge zur optic trüber Medien speziell kolloidaler Metallösungen, Ann. Phys., 25, 377-445, 1908.

Nessler, R., Weingartner, E., and Baltensperger, U.: Adaptation of dry nephelometer measurements to ambient conditions at the Jungfraujoch, Environ. Sci. Technol., 39, 2219-2228, 2005.

Pagels, J., Khalizov, A. F., McMurry, P. H., and Zhang, R. Y.: Processing of Soot by Controlled Sulphuric Acid and Water Condensation-Mass and Mobility Relationship, Aerosol Sci. Tech., 43, 629-640, doi:10.1080/02786820902810685, 2009.

Pan, X. L., Yan, P., Tang, J., Ma, J. Z., Wang, Z. F., Gbaguidi, A., and Sun, Y. L.: Observational study of influence of aerosol hygroscopic growth on scattering coefficient over rural area near Beijing mega-city, Atmos. Chem. Phys., 9, 7519-7530, doi:10.5194/acp-9-7519-2009, 2009.

Petters, M. D. and Kreidenweis, S. M.: A single parameter representation of hygroscopic growth and cloud condensation nucleus activity, Atmos. Chem. Phys., 7, 1961-1971, doi:10.5194/acp-71961-2007, 2007.

Pilat, M. J. and Charlson, R. J.: Theoretical and optical studies of humidity effects on the size distribution of hygroscopic aerosol, J. Rech. Atmos., 1, 165-170, 1966.

Randriamiarisoa, H., Chazette, P., Couvert, P., Sanak, J., and Mégie, G.: Relative humidity impact on aerosol parameters in a Paris suburban area, Atmos. Chem. Phys., 6, 1389-1407, doi:10.5194/acp-6-1389-2006, 2006.

Ran, L., Zhao, C. S., Xu, W. Y., Lu, X. Q., Han, M., Lin, W. L., Yan, P., Xu, X. B., Deng, Z. Z., Ma, N., Liu, P. F., Yu, J., Liang, W. D., and Chen, L. L.: VOC reactivity and its effect on ozone production during the HaChi summer campaign, Atmos. Chem. Phys., 11, 4657-4667, doi:10.5194/acp-11-4657-2011, 2011.

Roberts, G. C. and Nenes, A.: A continuous-flow streamwise thermal-gradient $\mathrm{CCN}$ chamber for atmospheric measurements, Aerosol Sci. Tech., 39, 206-221, 2005.

Schwartz, S.: The Whitehouse Effect-Shortwave radiative forcing of climate by anthropogenic aerosols: An overview, J. Aerosol Sci., 27, 359-382, 1996.

Seinfeld, J. H. and Pandis, S. N.: Atmospheric Chemistry and Physics, John Wiley \& Sons, Inc., New York, 1998.

Sheridan, P., Delene, D., and Ogren, J.: Four years of continuous surface aerosol measurements from the Department of Energy's Atmospheric Radiation measurement Program Southern Great Plains Cloud and Radiation Testbed site, J. Geophys. Res., 106, 20735-20747, 2001.

Wang, W., Rood, M., Carrico, C., Covert, D., Quinn, P., and Bates, T.: Aerosol optical properties along the northeast coast of North 
America during the New England Air Quality Study - Intercontinental Transport and Chemical Transformation 2004 campaign and the influence of aerosol composition, J. Geophys. Res., 112, D10S23, doi:10.1029/2006JD007579, 2007.

Xu, W. Y., Zhao, C. S., Ran, L., Deng, Z. Z., Liu, P. F., Ma, N., Lin, W. L., Xu, X. B., Yan, P., He, X., Yu, J., Liang, W. D., and Chen, L. L.: Characteristics of pollutants and their correlation to meteorological conditions at a suburban site in the North China Plain, Atmos. Chem. Phys., 11, 4353-4369, doi:10.5194/acp-114353-2011, 2011.

Yan, P., Pan, X., Tang, J., Zhou, X., Zhang, R., and Zeng, L.: Hygroscopic growth of aerosol scattering coefficient: A comparative analysis between urban and suburban sites at winter in Beijing, Particuology, 7, 52-60, 2009.

Yang, F., Tan, J., Zhao, Q., Du, Z., He, K., Ma, Y., Duan, F., Chen, G., and Zhao, Q.: Characteristics of $\mathrm{PM}_{2.5}$ speciation in representative megacities and across China, Atmos. Chem. Phys., 11, 5207-5219, doi:10.5194/acp-11-5207-2011, 2011.

Yuan, C.-S., Lee, C.-G., Liu, S.-H., Chang, J.-C., Yuan, C., and Yang, H.-Y.: Correlation of atmospheric visibility with chemical composition of Kaohsiung aerosols, Atmos. Res., 82, 663-679, 2006.

Zieger, P., Fierz-Schmidhauser, R., Gysel, M., Ström, J., Henne, S., Yttri, K. E., Baltensperger, U., and Weingartner, E.: Effects of relative humidity on aerosol light scattering in the Arctic, Atmos. Chem. Phys., 10, 3875-3890, doi:10.5194/acp-10-38752010, 2010.
Zieger, P., Weingartner, E., Henzing, J., Moerman, M., de Leeuw, G., Mikkilä, J., Ehn, M., Petäjä, T., Clémer, K., van Roozendael, M., Yilmaz, S., Frieß, U., Irie, H., Wagner, T., Shaiganfar, R., Beirle, S., Apituley, A., Wilson, K., and Baltensperger, U.: Comparison of ambient aerosol extinction coefficients obtained from in-situ, MAX-DOAS and LIDAR measurements at Cabauw, Atmos. Chem. Phys., 11, 2603-2624, doi:10.5194/acp11-2603-2011, 2011.

Zieger, P., Kienast-Sjögren, E., Starace, M., von Bismarck, J., Bukowiecki, N., Baltensperger, U., Wienhold, F. G., Peter, T., Ruhtz, T., Collaud Coen, M., Vuilleumier, L., Maier, O., Emili, E., Popp, C., and Weingartner, E.: Spatial variation of aerosol optical properties around the high-alpine site Jungfraujoch (3580 ma.s.1.), Atmos. Chem. Phys., 12, 72317249, doi:10.5194/acp-12-7231-2012, 2012.

Zieger, P., Fierz-Schmidhauser, R., Weingartner, E., and Baltensperger, U.: Effects of relative humidity on aerosol light scattering: results from different European sites, Atmos. Chem. Phys., 13, 10609-10631, doi:10.5194/acp-13-10609-2013, 2013. 